\title{
Fraser Syndrome with Major Hydrocephalus
}

\section{F. BENNAOUI1,2, N . EL IDRISSISLITINE1,2, H.JALAL ${ }^{3}$, F.M.R MAOULAININE 1,2}

1- Neonatal Intensive Care Department, Mohammed VI University Hospital and Research, Morocco

2- Marrakech School of Medicine, Cadi Ayyad University, Morocco

3- Radiology department, University Hospital Mohamed VI, Morocco

\section{INTRODUCTION}

$\square$ Fraser syndrome (Cryptophthalmos syndrome) is a rare malformative genetic syndrome described for the first time in 1962 by the British geneticist GR Fraser [1]. Its incidence is 0.043 per 10,000 live births, with autosomal recessive transmission [2].

$\square$ The authors report a case of Fraser syndrome with major hydrocephalus in order to recall the genetic, pathogenic, clinical and therapeutic aspects of this syndrome.

\section{CASE REPORT}

$\square$ We report the case of a female newborn, hospitalized in Intensive Neonatal Unit, Mohamed VI University Hospital, Marrakesh.

$\square$ The parents were nonconsanguineous; there was a similar case in siblings: a sister who died on the first day of life, having the same facial malformations according to the parents.

$\square$ The clinical examination had noted a polymalformative syndrome, including: a macrocrania, with a cranial perimeter at $48 \mathrm{~cm}$ (>97th percentile), a labiosphenoidal cleft. On the right eye: incomplete cryptophthalmos with the presence of an upper eyelid, without a palpebral fold and without an eyeball. In the left eye: aniridia (fig. 1). No other abnormalities in within the clinical examination except a syndactyly (Fig. 2).

$\square$ The cerebral CT scan: major hydrocephalus with a reduction of the cerebral parenchyma. (Fig. 3)

\section{$\square$ The karyotype was normal.}

$\square$ The treatement of our patient required a multidisciplinary approach.

$\square$ The evolution was fatal after 3 months.

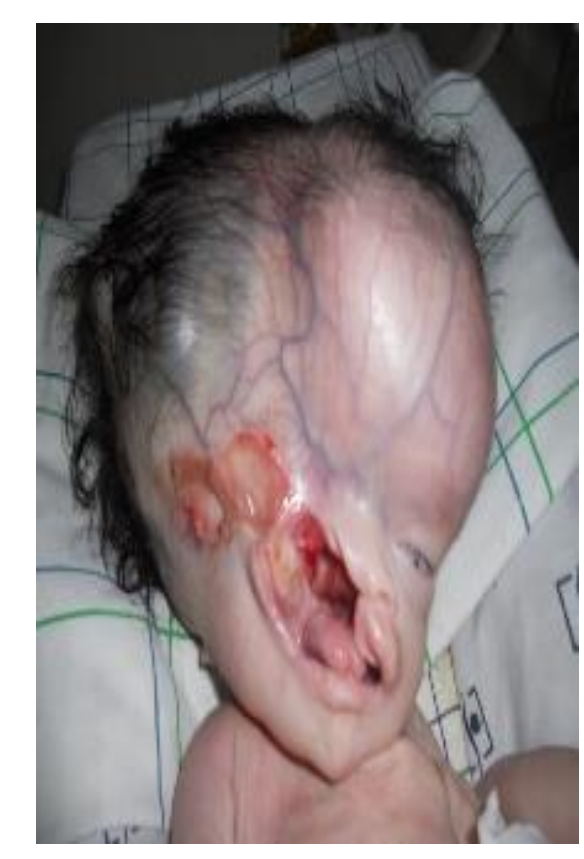

Figure1:

cryptophthalmos, labiosphenoidal cleft, macrocrania, agenesis of the nasal pyramid

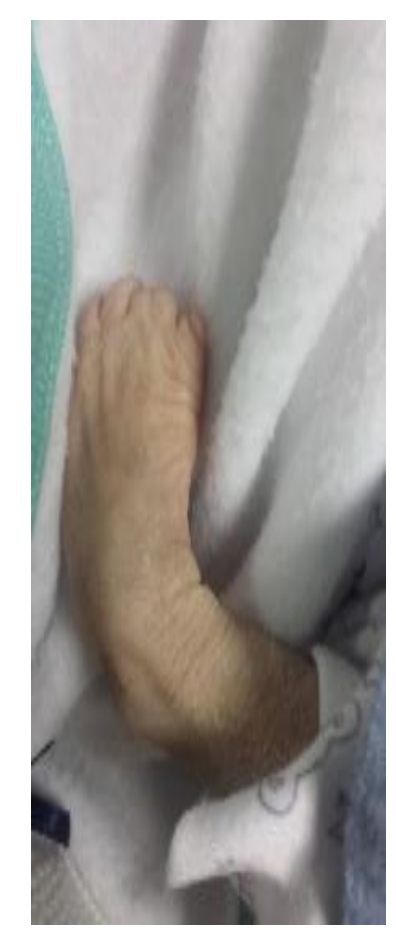

Figure 2: Syndacyly

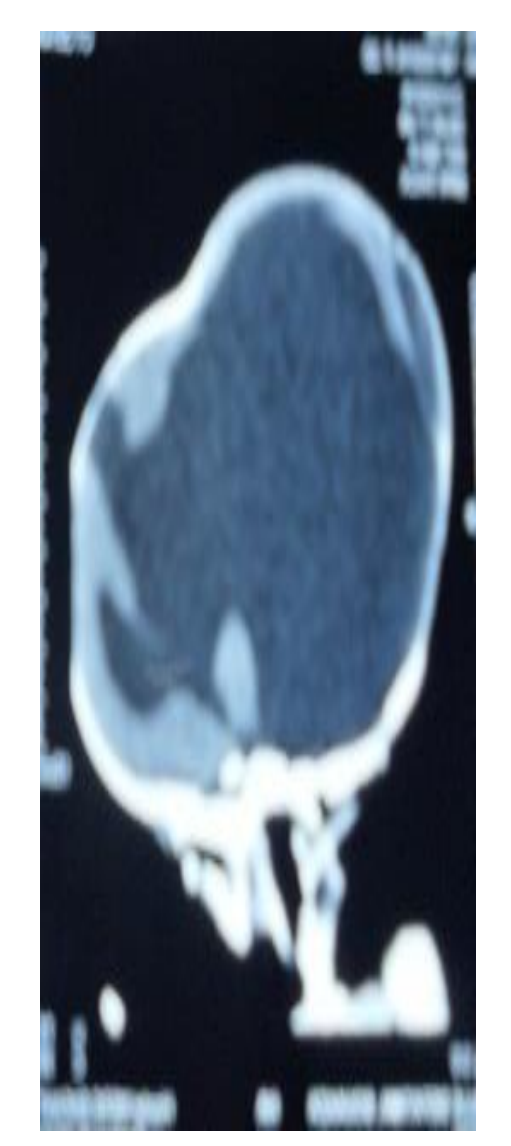

Figure 3: The cerebral CT scan: : major hydrocephalus with reduction of the cerebral parenchyma. a Fraser Syndrome (CryptophthalmosSyndactyly Syndrome) is a Rare Autosomal Recessive Polymalformative Syndrome;

$\square$ its Etiopathogenesis is Controversial. It could be due to a primary abnormality of eyelid formation with corneal and conjunctival epithelium metaplasia, a partially formed eyelid refusions- Or due to a failure of programmed cell death that would lead in utero to the opening of temporarily closed areas like: eyelids, fingers, vagina, toes...

$\square$ Karyotype is normal in this syndrome; recent research has led to the identification of the responsible gene: FRAS1 and research is under way to identify other genes and their homozygous mutations.

About $15 \%$ of the children described in the literature are born of consanguineous couples and the history of siblings with this syndrome is described.

$\square$ Its diagnosis is clinical, with major criteria and minor criteria.

पThe major criteria are: cryptophthalmos, syndactyly or genital abnormality.

DThe minor criteria include ear abnormalities, nose abnormalities, larynx and / or palate anomalies, skeletal abnormalities, umbilical hernia, renal agenesis and mental retardation.

TThe diagnosis is made in the presence of two major criteria and one minor criterion, or a major criterion and four minor criteria.

\section{CONCLUSION}

Fraser syndrome remains a major surgical and aesthetic challenge, particularly in developing countries. Need for prenatal diagnosis in order to decide on appropriate management. 